\title{
An innovation for flat traditional conventional footing
}

\author{
Aakriti Sharma ${ }^{1}$, Dr Prashant Garg ${ }^{2}$, Amandeep Singh ${ }^{2}$ \\ ${ }^{1}$ M.Tech Student,Geotechnical Department, Guru Nanak Dev Engineering College Ludhiana 141006, India \\ ${ }^{2}$ Professor, Civil Engineering Departement, Guru Nanak Dev Engineering College Ludhiana 141006, India
}

\begin{abstract}
:
Since their inception in the 1950s, shell foundations have grown in popularity over regular ones. In this paper, the ultimate load capacities of shell foundations on clay were determined by Numerical model tests. The results were compared with those for flat foundations with same base. The model test results were found using finite element analysis using program PLAXIS 2D. The experimental studies indicated that, the ultimate load capacity of shell footing on clay is higher than those on flat footing and the load settlement curves were significantly modified. The shell foundation over clay can be considered a good method to decrease the resulting settlement and material consumption at different thickness. Also rupture surface of shell upright and inverted system was significantly deeper than both normal footing. The numerical analysis helps in understanding the deformation behavior of the studied systems and identifies the failure surface of upright and inverted shell footing.
\end{abstract}

Keywords: Shell Foundation, Central shell angle, Load settlement curve, Plaxis 2D

\section{Introduction:}

Conical shell footing is a special type of foundation used for unique structures such as cooling towers, transmisson towers and heavy loaded structures. Shell foundations are explored where weak soil have to hold heavy loads. The design of shell foundation is mainly divided into two categories: soil design and structural design. Ultimate capacity and settlement characteristics of shell foundation have shown improved performance than conventional flat footing. A relentless effort to prevent depletion of natural resources via conservation, ethics of good economics, and creative aesthetic appeal are essentially three major engineering ideas favourable to selecting of shells. A shell foundation can also be used in an inverted position for structures such as guyed masts, silos and water tanks. This inverted shell has heavy meridonial tension at base and decreases upward. Also, these inverted conical structures are more efficient than conical shell structures.

\section{Model Rendering:}

Over conventional approaches, numerical shell modelling takes use of the widespread usage of contemporary computational power. Well defined shell forms can be used to study for evaluating the shell soil interaction models numerically. Here, three proposed shell models of flat, upright and inverted footing are presented using Input in PLAXIS 2D. 
1.

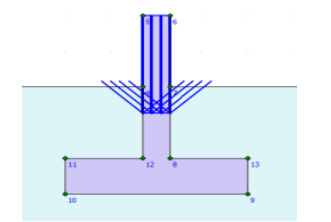

2.

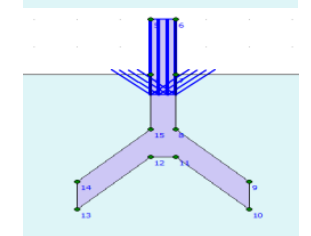

3.

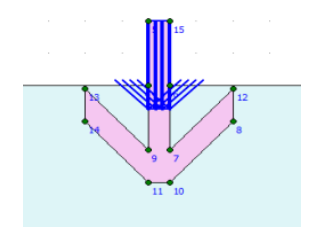

4.

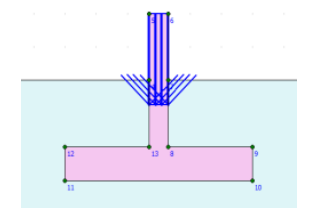

$\theta=83.66^{\circ}$

$\theta=180^{\circ}$

$\theta=106.96^{\circ}$

5.

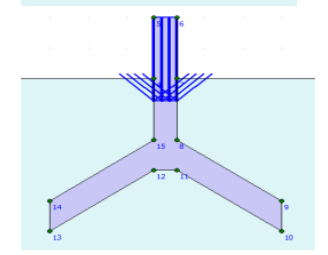

6.

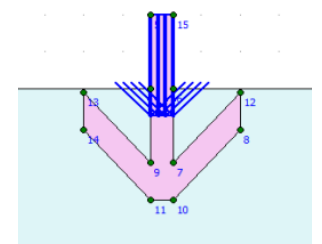

7.

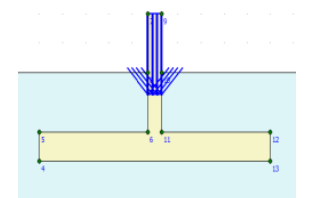

8.

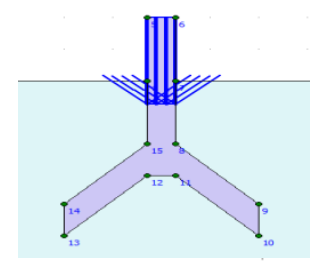

9.

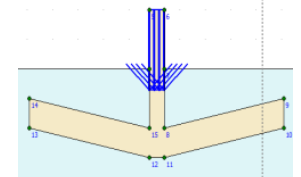

$\theta=155.97^{\circ}$

Fig 1 Nine model design with different central shell angle $(\theta)$

\subsection{Soil Properties:}

For the sake of simplicity and well established research findings one must go with the complex nature of soil structure behavior. In PLAXIS 2D there are soil models including Cam clay and modified cam clay (MCC). In the present study, an elastic perfectly plastic model following Mohr's Coulomb yield criterion is used. The following soil parameters should be known for using Mohr's Coulomb criterion that is cohesion (c), soil friction angle $(\phi)$, dilatancy $(\psi)$, Young's modulus $(\mathrm{E})$, and Poisson's ratio $(v)$ and thus its use is warranted.

Table 1 Soil Properties

\begin{tabular}{|l|l|l|}
\hline Soil Properties & $\underline{\text { Value }}$ & Units \\
\hline Unsaturated unit weight & 17 & $\mathrm{KN} / \mathrm{m}^{3}$ \\
\hline Saturated unit weight & 18 & $\mathrm{KN} / \mathrm{m}^{3}$ \\
\hline Permeability coefficient & 1.0 & $\mathrm{~m} / \mathrm{hr}$ \\
\hline Young's modulus & $4 \times 10^{4}$ & $\mathrm{kPa}$ \\
\hline Poisson's ratio & 0.3 & ----- \\
\hline Cohesion coefficient & 0.001 & $\mathrm{kPa}$ \\
\hline Friction angle & 33.68 & $\begin{array}{l}\text { degrees } \\
\left(^{\circ}\right)\end{array}$ \\
\hline Dilatancy angle & 2.0 & $\begin{array}{l}\text { degrees } \\
\left(^{\circ}\right)\end{array}$ \\
\hline
\end{tabular}

\subsection{Input in Plaxis program}

A new window is opened and model type "Plain strain" and Elements "15 nodes" are selected in the general settings box. It also contains fundamental modelling units and the size of the sketch area. Now, model is drawn and various parameters like standard fixities, boundary conditions, material properties and loading were added. PLAXIS $2 \mathrm{D}$ also supports a variety of data sets for soil and interfaces, plates, geogrids, embedded beam rows, and anchors. In the numerical investigation, strip footing with base $4 \mathrm{~m}, 6 \mathrm{~m}$ and $10 \mathrm{~m}$ were inserted $2 \mathrm{~m}$ 
deep into the tank $50 \times 20 \mathrm{~m}$ filled with a homogeneous clay layer. Also, the column of $0.6 \times 4 \mathrm{~m}$ is placed at the center of each strip footing. The goal of this study is to determine the displacements and stresses in the soil generated by the prescribed load. The geometry for all the three models of strip footing is similar to one other. In the figure the length of the column placed at the centre of conical base is inserted $2 \mathrm{~m}$ deep while the total length was $4 \mathrm{~m}$ same as flat conventional footing.

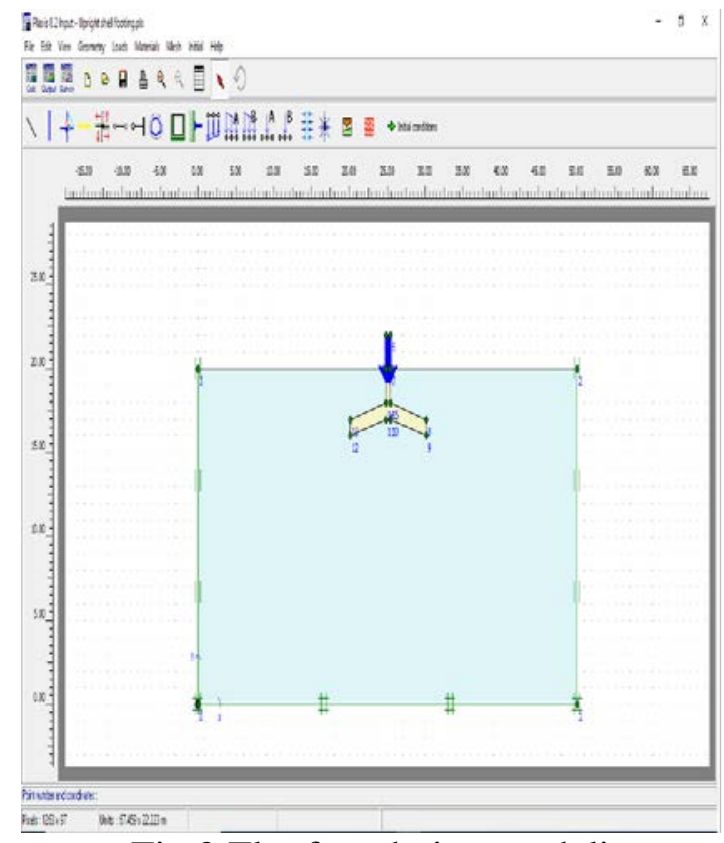

Fig 2 Flat foundation modeling

For loading conditions, the amount and direction of prescribed displacement can be set as $-0.1 \mathrm{~m}$ in the prescribed displacement dialogue box in both input fields in $\mathrm{Y}$ direction, signifying downward displacement of $0.1 \mathrm{~m}$. Also, all the $\mathrm{X}$ values have to remain zero signifying no displacement in $\mathrm{X}$ direction. These models were made to compare the results with flat conventional footing and upright shell footing in respect to load carrying capacity, settlement and economic behavior.

After making all the models in input data, a calculation program was started. With the help of this calculation program various phases such as staged construction, initial phase and consolidation phase etc were executed as desired in research work. Now click the Parameters tab, it contains the additional steps, loading input and iterative procedure etc. Maintain the default value of 250 for additional stages.

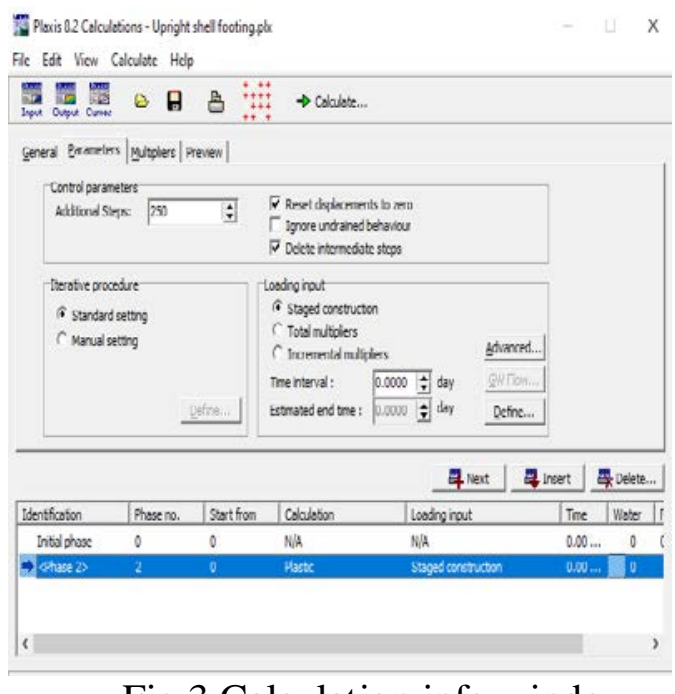

Fig 3 Calculation info window

\subsection{Output in plaxis program}

The outcomes of the computation procedure may be seen in the Output programme once it has been completed. The stresses and displacements in the whole geometry as well as any cross section of the model, if appropriate, may be shown in the output window as shown in fig 4, 5 and 6. 


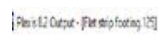

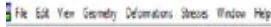

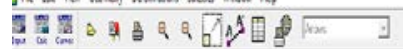

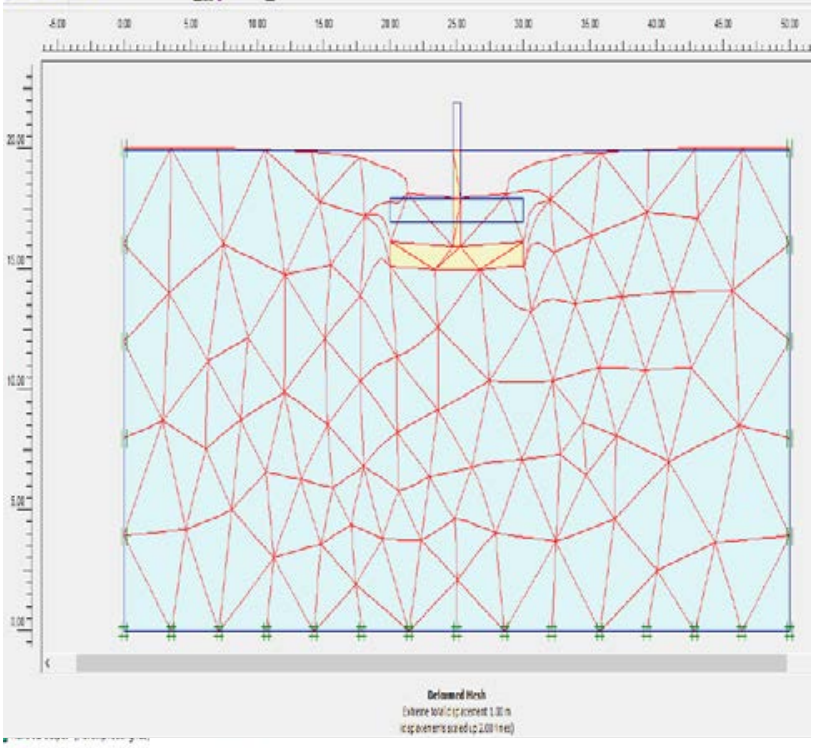

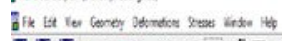

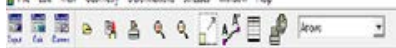

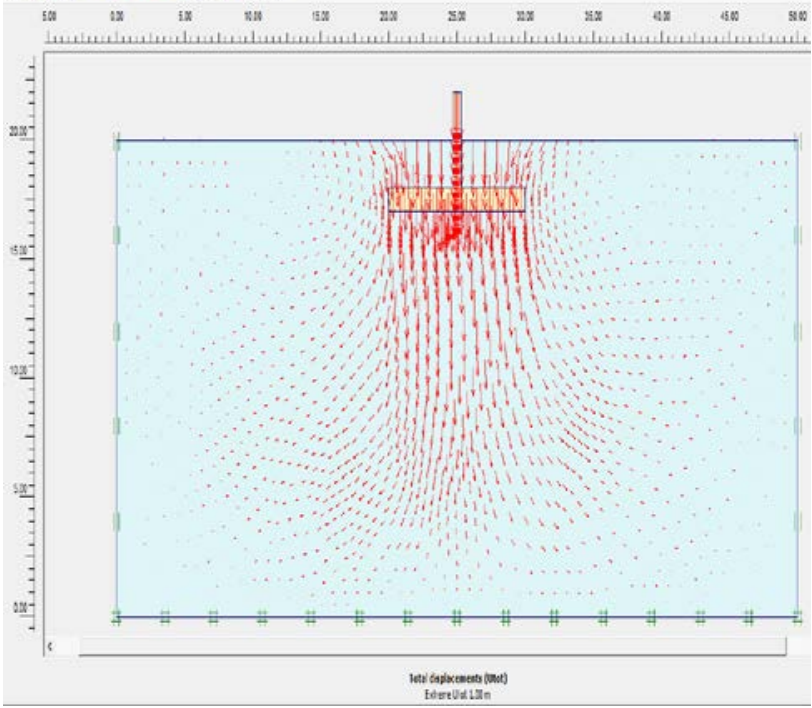

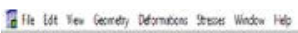

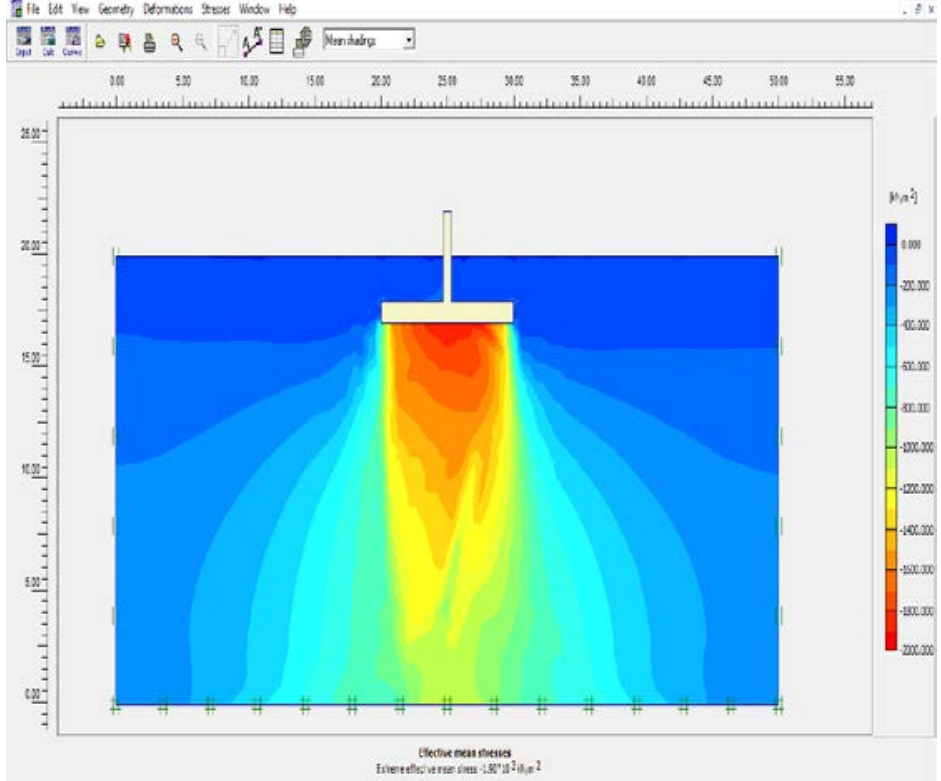

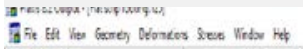

5y

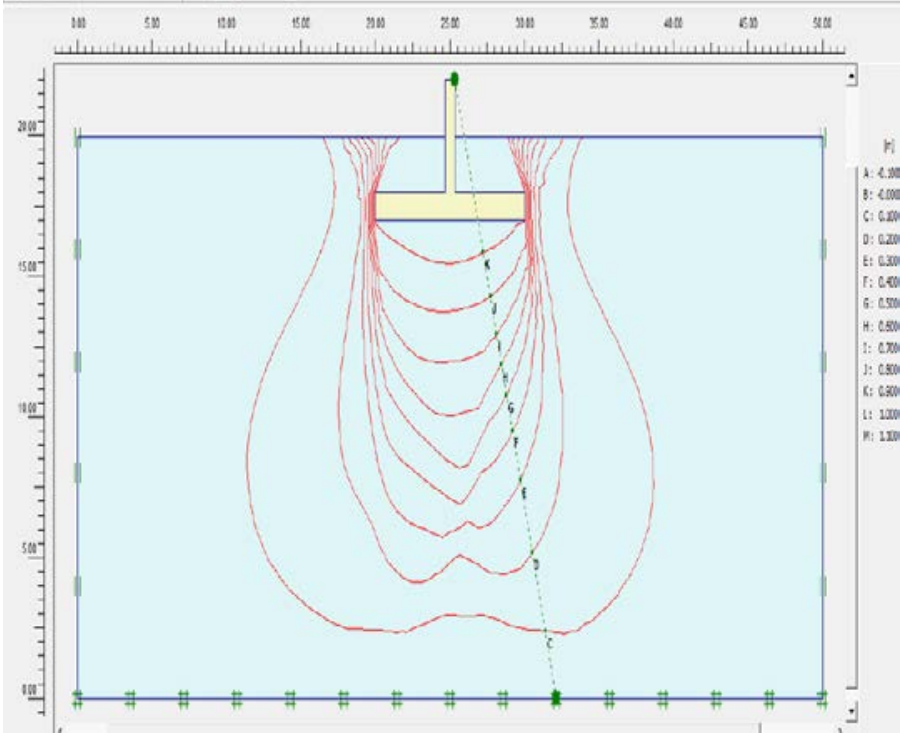

Fig 4 Output results of Flat foundation model showing deformed mesh, effective mean stress, total displacements and contour lines 


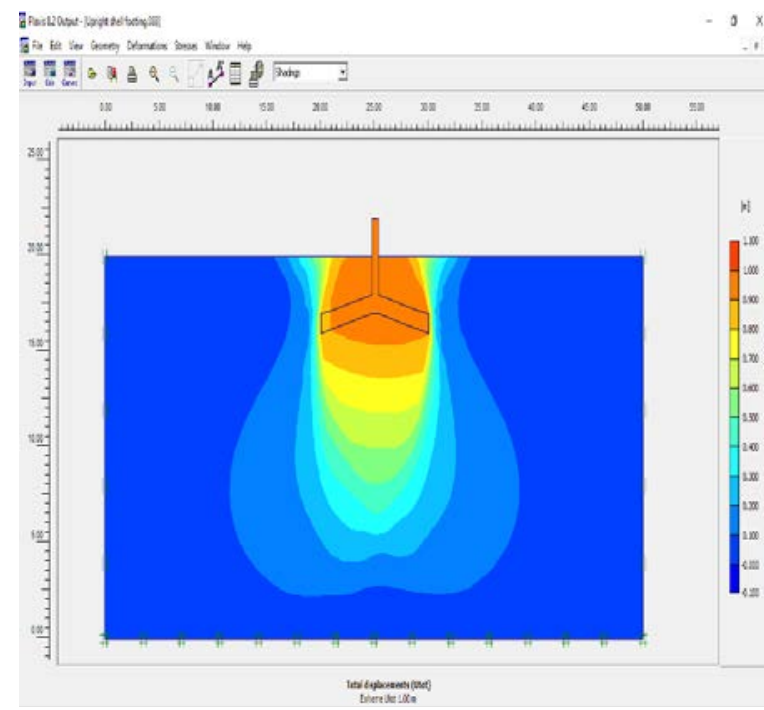

Fig 5 Output results of upright footing showing total displacements

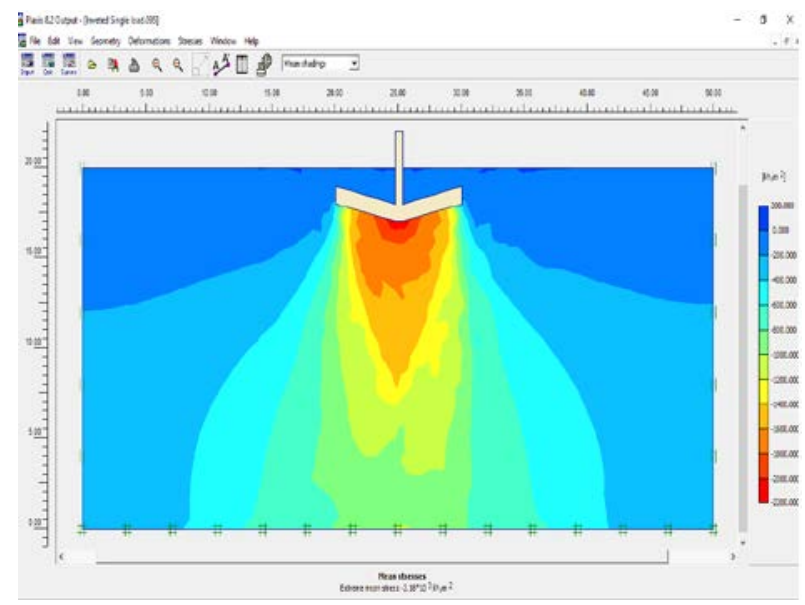

Fig 6 Output results of inverted footing showing mean stresses

\section{Results and Discussions}

The PLAXIS 2D software was used to do 13 prototype tests utilising the simple strain technique. The footings were inserted $2 \mathrm{~m}$ deep into the homogeneous clay having different thickness and central angle. As the calculation has gone enough steps as 250, the curve can be created using the icon showing curve. While generating the curve, individuals have to make a choice between $\mathrm{X}$-Y scatter. On the $\mathrm{X}$ axis one can choose displacement, velocity, multiplier, pore pressure and many more. In the same way on the $\mathrm{Y}$ axis displacement, multiplier, force etc can be chosen. In the same way on the $\mathrm{Y}$ axis displacement, multiplier, force etc can be chosen. Curves for flat, upright and inverted footing models with base $4 \mathrm{~m}, 6 \mathrm{~m}$ and $10 \mathrm{~m}$ were drawn and compared with each others. Three models include Flat with base $4 \mathrm{~m}$, upright footing with base $4 \mathrm{~m}$ and central angle 83.66 and also inverted footing same as upright footing dimension. This curve depicts that in case of inverted footing with central angle 83.66 has shown least settlement at greater load carrying capacity. The load taking capacity of inverted footing is $4.96 \%$ more than upright footing. Also upright footing shows much better load taking capacity as compared to flat footing. It is $22.27 \%$ greater than flat footing. One should prefer Shell footing instead of flat footing.

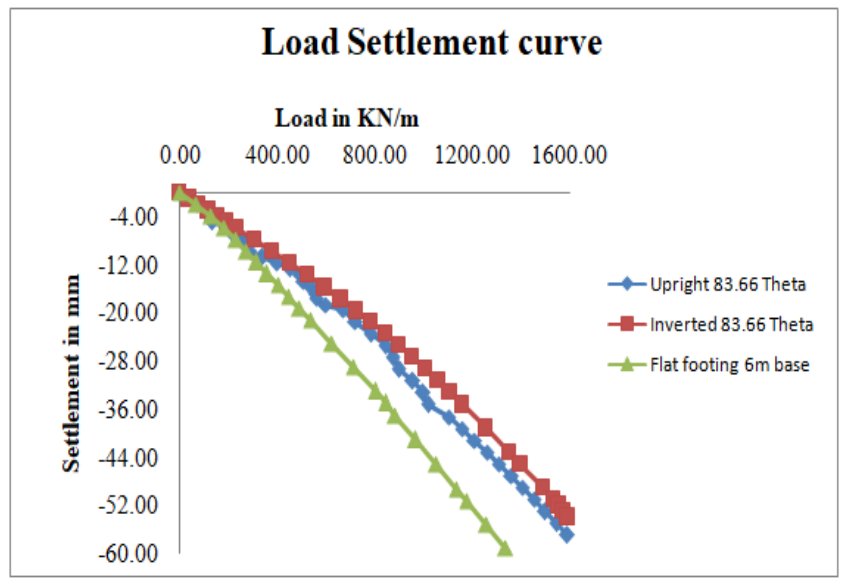

Fig 7 Load settlement curve for central shell angle $83.66^{\circ}$

This curve shows that inverted footing has least settlement with greater load carrying ability. Inverted footing has $8.76 \%$ more load bearing capacity than upright footing with the same dimension. Also, on the other hand upright footing has shown $6.40 \%$ more load bearing capacity. 


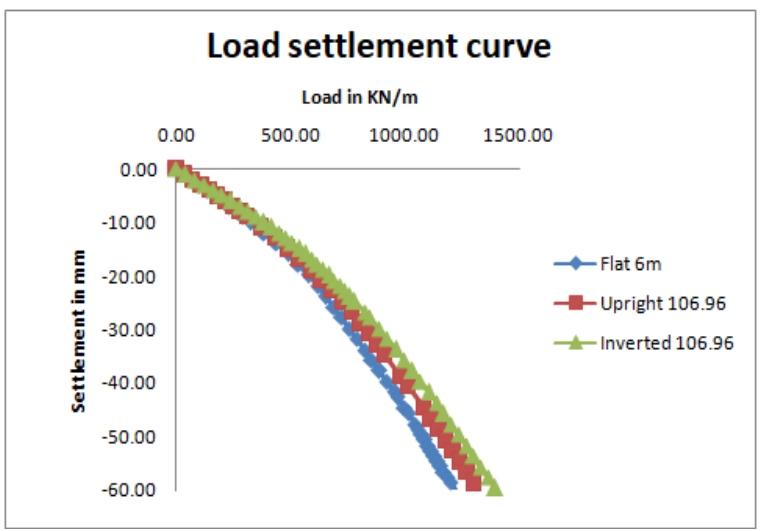

Fig 8 Load settlement curve for central shell angle $106.96^{\circ}$

In the curve shown below three other models i.e. flat footing with base $10 \mathrm{~m}$, upright footing with base $10 \mathrm{~m}$ having central angle $155.97^{\circ}$ and inverted footing with same dimensions as upright footing were examined. The curve obviously demonstrates that the load carrying performance of inverted footing is greater than that of the other two kinds. Inverted footing has a load bearing potential that is $15.69 \%$ more than upright footing.

In comparison to flat and upright footing, upright footing shows $21.35 \%$ more load bearing capacity than flat footing.

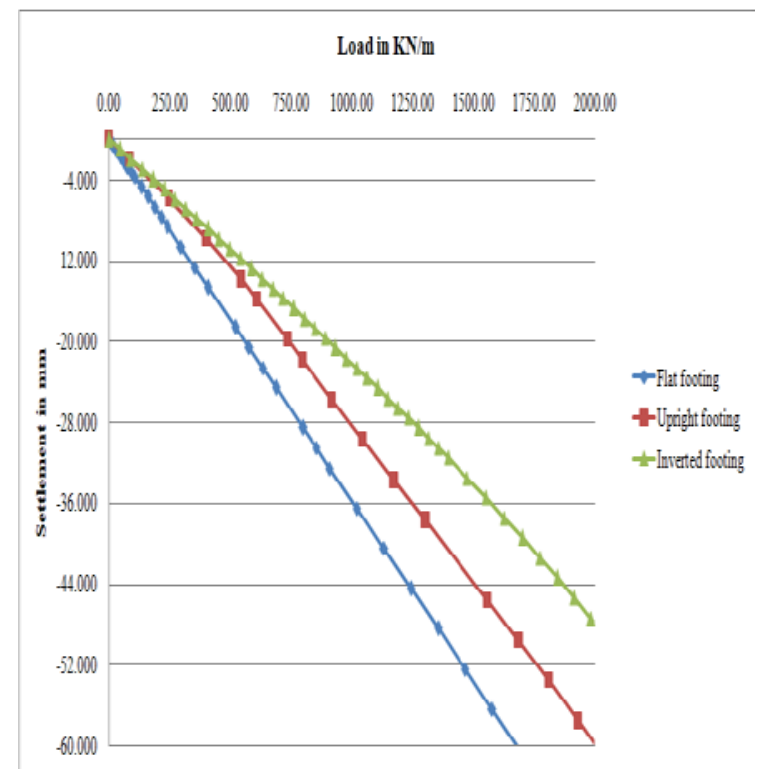

Fig 9 Load settlement curve for central shell angle $155.97^{\circ}$

\section{Conclusions}

The load bearing capacity behaviour of flat, upright and inverted footing inserted $2 \mathrm{~m}$ deep into the homogeneous layer of clay was investigated and also the findings are compared with the available literature. The following observations have been made based on the results of current scientific effort.

a) All of the established Simulation model accurately simulated the behaviour of shell footings and were found to be in excellent agreement with the results of the existing literature papers reviewed. Preliminary FE model analysis showed the bearing capacity of inverted footing is more than upright footing.

b) The load carrying capacity of shell footing with upright and inverted orientation increases with increase in the central shell angle. From the present study it is found that with the increase of $83.66^{\circ}, 106.96^{\circ}$ and $155.97^{\circ}$ of central shell angle the load taking capacity increases by $4.96 \%, 8.76 \%$ and $15.69 \%$ respectively in comparison of inverted footing with upright footing.

c) With the application of applied load a linear fashion behaviour has been noticed for developing contact pressure in the homogeneous tank filled with clay for shell footing in comparison to flat footing. Also for the inverted footing more contact pressure lies in the center region instead of moving towards the ends of footing as in case of flat footing models.

d) The suggested investigation shows that the rupture surface for shell footing is deeper than for flat footing. As a result, the ultimate load bearing strength of shell footing is bigger than that of flat ordinary footing.

e) The numerical research inquiry confirmed that using Mohr-failure 
Coulomb's criterion on an elastic completely flexible soil model produced a fair depiction of the behaviour of soilstructure interaction in a cohesionless soil like clay.

\section{Recommendations for future research:}

The behaviour of a shell foundation under dynamic loads to simulate wind or seismic stresses must be investigated. The construction of tall slender structures with thin-shell foundation supports, such as silos, tanks, and chimneys, frequently necessitates a lateral load analysis.With lateral load analysis bearing capacity and settlement equations may be influenced by a variety of circumstances. Secondly, develop safety elements for shell foundation used beneath retaining wall structures, such as sliding, overturning, and bearing capacity. An investigation of the three forms of lateral earth pressures: at rest, active, and passive can be calculated. After that total force obtained may be investigated to find the factor of safety.

Declaration of Competing Interest

The authors declare that they have no known competing financial interests or personal relationships that could have appeared to influence the work reported in this paper.

\section{References:}

[1] Abdel-Rahman M. Geotechnical behavior of shell foundations. Ph.D Thesis.Department of Civil Engineering, Concordia University, Montréal, Canada; 1996.

[2] Azzam W.R., Nasr A.M., (2015), "Bearing capacity of shell strip footing on reinforced sand" Journal of Advanced Research (2015) 6,727-737

[3] Jose Tinsa, Philip G Joe, (2017), "Experimental and numerical analysis of conical shell strip footing reinforced in multi layered soil”. International Journal of Engineering and Management Research Page Number: 340-344

[4] Kumar M., Subagiriraj M. (2019), "Experimental Investigation of Various Shell Footings in Cohesive and Cohesionless Soil" International Journal of Civil, Environmental and Agricultural Enginnering Pg.no. 67-77

[5] Plaxis Version 8 Reference ManualCivil IITB Page 1-200

[6] Ramesh M, Joy M Blessy (2015), "Experimental Study on Conical Shell Footing”. International Journal of Engineering Research \& Technology (IJERT) ISSN: 2278-0181 Vol. 4 Issue 06, June-2015

[7] Rinaldi Remo (2012), "Inverted Shell Foundation Performance In Soil”, A Ph.D thesis at Concordia university, Montreal, Canada 